\title{
Seed Layer Assisted Growth of Chemical Bath Deposited ZnO Nanorods : Influence of Seed Layer Thickness
}

\author{
R. A. Rahman, M. A. Zulkefle, S. H. Herman and R. I Alip
}

\begin{abstract}
Synthesis of zinc oxide ( $\mathrm{ZnO}$ ) nanorods by chemical bath deposition (CBD) was presented in this study. In this study, indium tin oxide (ITO) was used as the substrate, and the thickness of $\mathrm{ZnO}$ seed layer was varied, by varying the number of spin coating layers $(1,2,3,4$ and 5 layers) while other growth parameters were remained constant. Based on the result obtained, the quality of $\mathrm{ZnO}$ nanorods was when te number of seed layer was increase. Based on the transmittance and absorbance value obtained, the optical energy band gap for all the growth $\mathrm{ZnO}$ nanorods were calculated. All of the $\mathrm{ZnO}$ nanorods thin films have the optical energy band gap in the range of 3.34-4.10 eV, which is approaching the theoretical band gap of $\mathrm{ZnO}(3.37 \mathrm{eV})$.
\end{abstract}

Index Terms - chemical bath deposition (CBD), seed layer, solgel spin coating, $\mathrm{ZnO}$ nanorod

\section{INTRODUCTION}

$\mathrm{T}$ HE EVOLUTION of morphology, microstructures and nanostructrures of films have essential effects on the performance of functional surfaces. Materials can be classified as nanostructured, when materials their structure were in nanometer scale (1-100) at least in one dimension, two or three domensions [1]. In recent years, nanostructured materials had drawn an extensive interest among researchers, either in basic scientific research or commercial development area. Novel properties and superior performance in certain areas have become a motivation among researchers to explore and study nanostructured material. The study of nanostructures, which is known as nanotechnology, has widely evolved in many applications, especially in traditional science and engineering field [2-4].

There are lot of nanostructures that had been explored in previous studies. Nanotube, nanorods, nanosheet, nanocomb, nanowire, as well as nanoflower are parts of nanostructures that are common in nanostructure fields [5-7]. There are many materials that could produce these type of nanostructures such as titanium dioxide $\left(\mathrm{TiO}_{2}\right)$, nickel oxide $(\mathrm{NiO})$, zinc oxide

This manuscript is submitted on $30^{\text {th }}$ October 2019 and accepted on $6^{\text {th }}$ April 2020. R. A. Rahman, M.A. Zulkefle. S. H. Herman and R. I. Alip are from Integrated Sensor Research Group, Faculty of Electrical Engineering, Universiti Teknologi MARA, 40450 Shah Alam, Selangor, Malaysia. (e-mail: rohanieza.abdrahman@gmail.com).

1985-5389/C 2021 The Authors. Published by UiTM Press. This is an open access article under the CC BY-NC-ND license (http://creativecommons.org/ licenses/by-nc-nd/4.0/).
$(\mathrm{ZnO})$, graphene, and silicon [8-10]. Among all these materials, $\mathrm{ZnO}$ is an intriguing materials that posseses numerous family of nanostructures. Many studies shows that $\mathrm{ZnO}$ could be synthesized to produce nanowires, nanoring, nanobelts, nanocombs, and also nanorods [11-13].

The nanostructures of Zno could be prepared based on the need and requirements of the applications. A recent research has demonstrated that creation of highly oriented and ordered array of $\mathrm{ZnO}$ nanostructures has greatly stimulate interest in development of novel devices [15]. Nanorods is one of the $\mathrm{ZnO}$ nanostructures that had been greatly explored by researchers. $\mathrm{ZnO}$ nanorods is a one-dimensional (1D) type of nanostructures, with fascinating physical properties. Furthermore, 1D structure such as $\mathrm{ZnO}$ nanorods is believed to have more surface volume to ratio than 2-dimensional (2D) structure, hence this type of nanostructures could enhance and increase the sensitivity in many applications [14]. However, this ability is depending on the desired application

$\mathrm{ZnO}$ nanorods could be produced via various chemical, physical and electrochemical deposition techniques such as chemical vapor deposition (CVD), electrochemical deposition (ED), and chemical bath deposition (CBD) [16-18]. Some of these methods required very high temperature and has complicated handling. Hence, CBD method is more preferable this is because it low temperature $\left(60-100^{\circ} \mathrm{C}\right)$, low cost, high yield, controllable, excellent well-defined structure and simple method.

CBD is a chemical-wet method that has the ability to control the nanostructures of the materials [19]. As reported by $\mathrm{Q}$. Li et. al, well-allign $\mathrm{ZnO}$ nanorods can be produced via $\mathrm{CBD}$ method [20]. In their study, the concentration of the solutions were varied. By varying the concentration of the solution, they managed to obtain dense and well-aligned $\mathrm{ZnO}$ nanorods when the concentration was being increased. The properties of $\mathrm{ZnO}$ nanostructures are highly dependent on its morphology and shape [21]. This morphology can be controlled using few parameters. It is evident that experimental condition such as growth temperature, growth time, precursor concentration and $\mathrm{pH}$ value of the solution could alter the $\mathrm{ZnO}$ nanorods. In a study reported by $\mathrm{D}$. Polsongkram et. al, $\mathrm{ZnO}$ nanorods obtained in their study became larger when the deposition 
temperature was reduced from $75^{\circ} \mathrm{C}$ to $65^{\circ} \mathrm{C}$ [22]. Besides that, approach such as using seed layer as the base for the growth of $\mathrm{ZnO}$ nanorods is one of the crucial factor to produce well- allign and high quality nanorods [23]. J. B. Cui also stated that the presence of seed layer will enhance the growth of anaorod and thus determine the size of the grown $\mathrm{ZnO}$ nanorods. Considering this, the thickness of the seed layer was believed to have significant effect towards the growth of nanorod. Wellallign $\mathrm{ZnO}$ nanorods could be controlled and produced by optimizing the thickness of the seed layer, as reported by S. Pokai et. al [24].

The number of layers were varied for the purpose of exploring its effect towards morphological, thickness, optical and structural properties. The properties and characteristics of the $\mathrm{ZnO}$ nanorods were characterized using field emission scanning electron microscope (FESEM), surface profilometer (SP), ultraviolet-visible spectrometer (UV-Vis) and x-ray diffraction (XRD).

\section{EXPERIMENTAL}

$\mathrm{ZnO}$ nanorods was grown on the ITO substrate by a two-step procedure process. . In the first step, $\mathrm{ZnO}$ was deposited onto the substrate, to be the seed layer using sol-gel spin coating technique. Then the $\mathrm{ZnO}$ nanorods were deposited on the seed layer using CBD method. This two-step process of growing $\mathrm{ZnO}$ nanorods is thoroughly explained in detail in the next subsection.

\section{A. ZnO Seed Layer Deposition Process}

ITO substrate with the dimension of $2 \times 1 \mathrm{~cm}$ was cleaned using standard cleaning process by immersing it in $100 \mathrm{~mL}$ beaker containing ethanol solution $\left(\mathrm{C}_{2} \mathrm{H}_{5} \mathrm{OH}\right)$ and was sonicated for duration of 10 minutes. After that, $\mathrm{C}_{2} \mathrm{H}_{5} \mathrm{OH}$ was removed, and deionized water (DI water) was poured into the beaker to undergo second sonicating process. Then the cleaned ITO was blown using Argon (Ar) gas, to ensure that all the moisture was eliminated.

To prepare the $\mathrm{ZnO}$ solution, precursor zinc acetate dihydrate $\left(\mathrm{ZnAc}_{2}\right)$ was dissolved in 2-methoxyetanol $\left(\mathrm{C}_{3} \mathrm{H}_{8} \mathrm{O}_{2}\right)$ and MEA was used as stabilizer. This $0.4 \mathrm{M}$ solution was magnetically stirring and $80^{\circ} \mathrm{C}$ heat was applied. After 3 hours, the heat was switched off, and the solution was stirred at room temperature for 24 hours, to get a clear and homogenous solution.

For the spin coating deposition process, 10 drops of $\mathrm{ZnO}$ solution were dropped onto the center of ITO substrate and spun at $3000 \mathrm{rpm}$ for 60 seconds duration. After that, the spin coated $\mathrm{ZnO}$ was dried in a furnace for 10 minutes at $150{ }^{\circ} \mathrm{C}$ sto remove all the moisture and residual from the solvent.

In this study number of seed coating layers were varied, where 1, 2, 3, 4 and 5 different layers were fabricated. Each of the seed layer was dried, before the next layer was deposited. At the end, annealing process was performed. Annealing process is important as it can help restructuring abd rearranging the atoms that may resulted in materials with better properties of the deposition, for the final step, the annealing process is important to restructure the atom arrangement for better properties.

\section{B. Growth of ZnO Nanorods}

$0.1 \mathrm{M}$ growth solution was prepared by dissolving zinc nitrate hexahydrate $\left(\mathrm{Zn}\left(\mathrm{NO}_{3}\right)_{2} \cdot 6 \mathrm{H}_{2} \mathrm{O}, \quad 99 \%\right)$ and hexamethylenetetramine $\left(\left(\mathrm{CH}_{2}\right) 6 \mathrm{~N}_{4}, 99.5 \%\right)$ in deionized water (DI water). The molar ratio of $\mathrm{Zn}\left(\mathrm{NO}_{3}\right)_{2} \cdot 6 \mathrm{H}_{2} \mathrm{O}$ and $\left(\mathrm{CH}_{2}\right) 6 \mathrm{~N}_{4}$ was standardized to $1: 1$, and DI water was added until $500 \mathrm{~mL}$ solution was prepared. This solution was sonicated for 30 minutes at $50{ }^{\circ} \mathrm{C}$. Then, the aging process was continued by stirring the solution at $300 \mathrm{rpm}$ at room temperature. When the solution was ready, it was poured into 5 different schott bottles with the volume of $100 \mathrm{~mL}$ in each bottles. ITO substrate with different number of $\mathrm{ZnO}$ seed layers were placed upside down in the schott bottles filled with the $\mathrm{ZnO}$ solution.

All of the schott bottles were put in the water bath that was already preheated at $95^{\circ} \mathrm{C}$. The growth process of $\mathrm{ZnO}$ nanorod swas set for 1 hour, where all the grown samples were taken out after the growing process completed. Then the samples were dried at $150^{\circ} \mathrm{C}$ for 10 minutes. Finally, the dried samples were annealed at $500{ }^{\circ} \mathrm{C}$ for 1 hour. The growth mechanism of $\mathrm{ZnO}$ nanorods using chemical bath deposition can be described using chemical equation below :

$$
\begin{aligned}
& \mathrm{Zn}\left(\mathrm{NO}_{3}\right)_{2}+\mathrm{C}_{6} \mathrm{H}_{12} \mathrm{~N}_{4} \leftrightarrow\left[\mathrm{Zn}\left(\mathrm{C}_{6} \mathrm{H}_{12} \mathrm{~N}_{4}\right)\right]^{2+}+2 \mathrm{NO}_{3}{ }^{-} \\
& \mathrm{C}_{6} \mathrm{H}_{12} \mathrm{~N}_{4}+4 \mathrm{H} 2 \mathrm{O} \leftrightarrow \mathrm{C}_{6} \mathrm{H}_{12} \mathrm{~N}_{4}^{+}+4 \mathrm{OH}^{-} \\
& {\left[\mathrm{Zn}\left(\mathrm{C}_{6} \mathrm{H}_{12} \mathrm{~N}_{4}\right)\right]^{2+}+4 \mathrm{OH}^{-} \leftrightarrow \mathrm{Zn}(\mathrm{OH})_{4}{ }^{2-}+\mathrm{C}_{6} \mathrm{H}_{12} \mathrm{~N}_{4}} \\
& \mathrm{Zn}(\mathrm{OH})_{4}{ }^{2-} \leftrightarrow \mathrm{Zn}^{2+}+4 \mathrm{OH}^{-} \\
& \mathrm{Zn}^{2+}+2 \mathrm{OH}^{-} \leftrightarrow \mathrm{ZnO}+\mathrm{H}_{2} \mathrm{O} \\
& \mathrm{Or} \mathrm{Zn}^{2+}+2 \mathrm{OH}-\leftrightarrow \mathrm{ZnO}(\mathrm{OH})_{2}+\mathrm{H}_{2} \mathrm{O} \leftrightarrow \mathrm{ZnO}+\mathrm{H}_{2} \mathrm{O}
\end{aligned}
$$

\section{Characterization of ZnO Nanorods Thin Film}

To examine the morphological of the grown $\mathrm{ZnO}$ nanorods, field emission scanning electron microscope (FESEM) was used. To study the optical properties, ultraviolet-visible spectrometer (UV-Vis) was chosen to determine the samples' transmittance, absorbance, as well as the optical band gap. For structural properties, the crystallinity of the prepared thin films was examined using $\mathrm{x}$-ray diffraction (XRD) while the thin film thickness was measured by a surface profiler.

\section{RESULTS AND DISCUSSIONS}

TABLE I

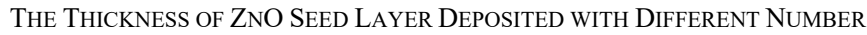
OF LAYERS

\begin{tabular}{cc}
\hline \hline NuMBER OF LAYER & Thickness (nm) \\
\hline 1 & 58.52 \\
2 & 123.23 \\
3 & 195.03 \\
4 & 236.85 \\
5 & 384.2 \\
\hline \hline
\end{tabular}

Table 1 shows the different thickness value that were attained when the number of seed layers were varied. According to the results obtained using surface profilometer (SP), the thickness of the films changes significantly with the different number of seed layers. The thickness measurement was performed to 
determine either the different number of seed layers would affect the thickness of the seed layer. For the thickness determination process, only the thickness of the different layer of seed layers were measured. During the measurement, three different spots were taken, then the average thicknesses for these three spots were calculated and tabulated in the Table 1.

As can be observed, the thickness value is increased, when the number of seed layer is increased. Notable changes were discovered when the deposition layer was increased from 1 to 2 layers. The same condition happen when further layers were deposited, which is the thickness change from $123.23 \mathrm{~nm}(2$ layers) to $384.62 \mathrm{~nm}$ (5 layers). This obvious changes proved that the film become thicker when more layers been deposited on the existing layer. This condition lead the increase number of $\mathrm{ZnO}$ particles settling on the substrate, thus, the film thickness would rise, significant with the increment number of $\mathrm{ZnO}$ particles [25]. Other than that, the increment of the thickness with the increase of seed layer might attribute from the drying effect. M. Addamo et al, reported in their study that when the layers is dried step-by-step, each of the layer would grew over an irregular and preformed crystalline surface, which will resulted larger final thickness [26].

As the number of seed layer was increased to 5 layers, the growth of nanorods become more uniform and densely packed. We can also observe the changes in the diameter of the nanorods.

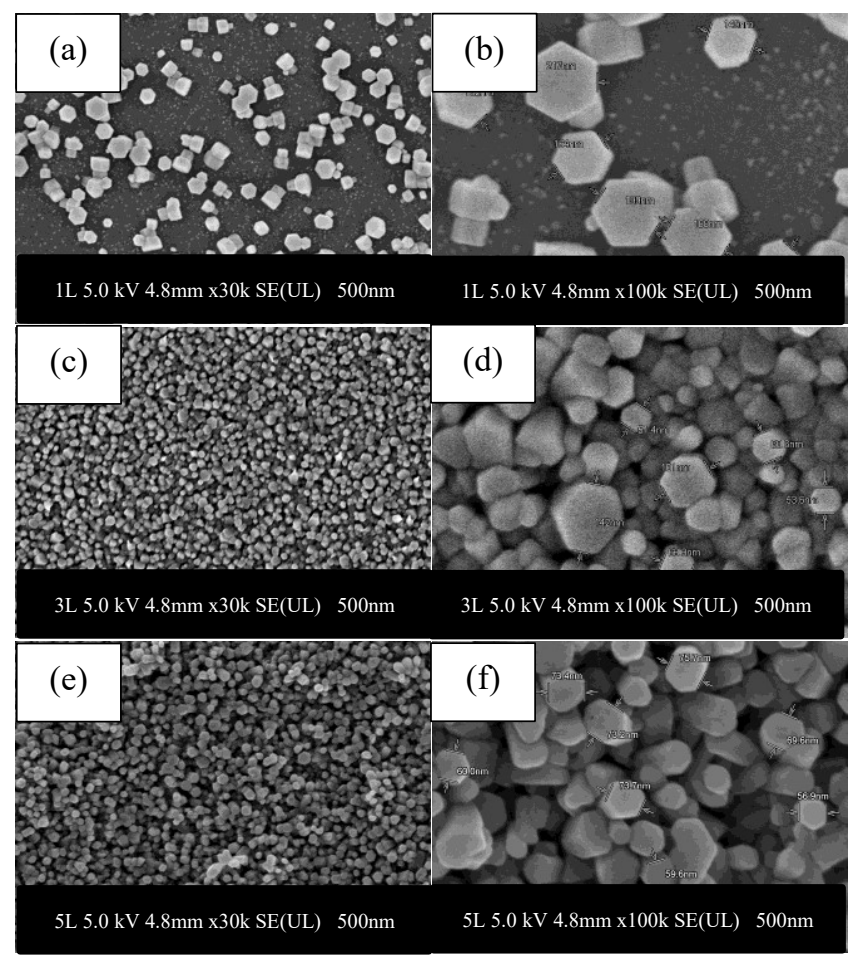

Fig. 1.The difference number of seed layer produce different diameter size of nanorods. Fig. 1 (a) is the $\mathrm{ZnO}$ nonorod grown at 1 layer of seed layer, Fig. 1 (b) diameter of nanorods 1 layer seed layer, Fig.1. (c) $\mathrm{ZnO}$ nanorods grown on 3 layers of seed layer, Fig. 1 (d) nanorods diameter for $\mathrm{ZnO}$ on 3 layers of seed layer, Fig. 1. (e) growth of $\mathrm{ZnO}$ nanorods on 5 layer seed layers and Fig. 1 (f) diameter value for $\mathrm{ZnO}$ nanorods on 5 layer seed layer
TABLE II

AVERAGE OF Diameter VALUES FOR ZNO NANORODS GROWN ON DIFFERENT LAYER OF SEED LAYER

\begin{tabular}{cc}
\hline \hline NUMBER OF LAYER & Average Diameter (nm) \\
\hline 1 & 179.56 \\
3 & 79.57 \\
5 & 67.76 \\
\hline \hline
\end{tabular}

We can also observe the changes in the diameter of the nanorods. Based on the results, the diameter of the nanorods decrease, inversely proportional with the number of seed layers. The diameter values for $\mathrm{ZnO}$ nanorods grown on 1 layer, 3 layer and 5 layers of seed layer are recorded in Table 1. Distribution and diameter of the nanorods changes might due to the differentiation of seed layer's thickness. B. Ikizler claimed that the surface seed of the parent seeds may serve as nuclei for further growth of the rods [28]. This statement can be referred to explain that the uniformity of nanorods distribution improve when the number of the seed layer is increased.

Increasing number of seed layer would produce uniform surface of seed layer, thus dense and uniform nanorods may be produced because nanorods will grown based on the seed layer that act as the nuclei. A contrast changes was observed, between surface morphology of 1 layer seed layer, and 5 layer of seed layers in Fig. 2 (a) and (b). The decreasing value of the nanorods diameter might related to the growth process, where there are multiple rod that originate from a single seed, despite the general explanation, which each of the rod originates from a single seed. The growth from the surface nuclei seems to have two different consequences, which is misalignment of the rod and the decreas of the rod diameter, as describe by B. Ikizler et al [27]. This description is an agreement to the results obtained in this study, which the diameter of the rod decrease, as the number of layer is increased. In addition, it also could be observed that there are misalignment of few rods, which prove that there are multiple rods might originates from a single seed.

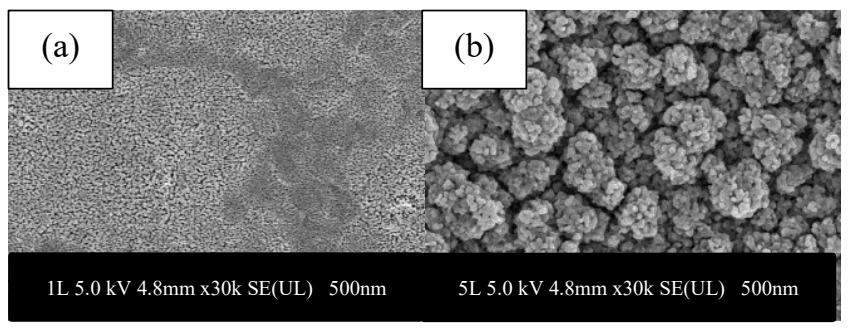

Fig. 2. (a) Surface morphology of 1 layer of seed layer and (b) FESEM images for 5 layer seed layers.

To investigate the effect of the number of seed layers towards crystallinity of $\mathrm{ZnO}$ nanorods, XRD analysis was conducted. Based on the results shows in Fig. 3, it could be observed that all of the $\mathrm{ZnO}$ shows crystalline structure. All of $\mathrm{ZnO}$ nanorods films exhibit (100), (002) and (101) crystalline peak. The (002) peak represent the structural characteristics of $\mathrm{ZnO}$ particles in c-direction, the growth direction of the nanorods due to the minimum energy of the plane. 


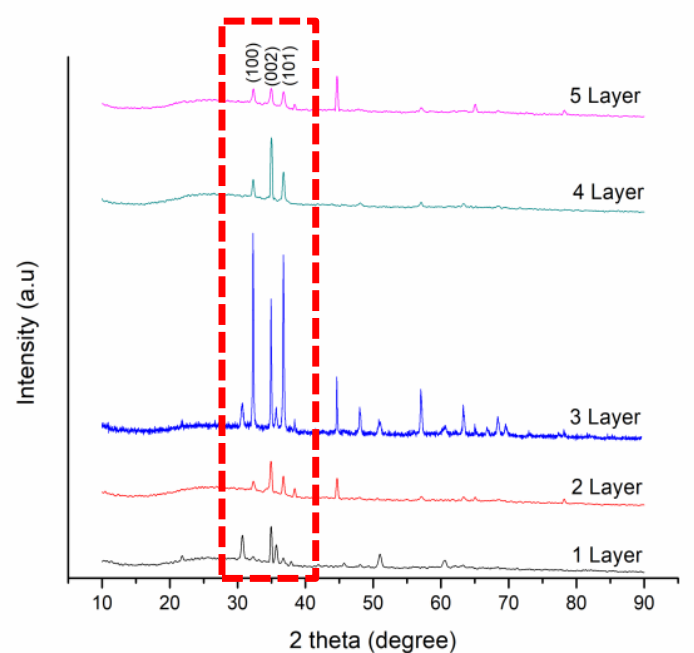

Fig. 3. X-ray diffraction patterns of $\mathrm{ZnO}$ nanorods grown at various layers of seed layers.

The presence of peak (002) in all of the growth thin films indicates that the growth direction is in the perfect alignment [28]. Besides (002) peak, the growth in direction other than the c-direction is (100) and (101) peak. These peaks are normalized by the intensity of (002) peak. As can be observed, (100), (002) and (101) peak were improved when the number of seed layer was increased. The highest peak intensity could be seen when $\mathrm{ZnO}$ grown on 3 layers of seed layer. The increase of peak intensity is reasoning from the thickness of the seed layer, that affect the degree of the crystallinity. Crystallinity of the seed layer improved with the increment number of the layers, hence lead to the higher peak intensity for $\mathrm{ZnO}$ nanorods.

The improvement of this crystallinity phase might reasoning from the crystallinity and thickness of the seed layer [29]. S. Pokai stated that the cumulative energy on $\mathrm{ZnO}$ surface will increase when the $\mathrm{ZnO}$ seed layer is increased, thus will resulting in high crystallinity of $\mathrm{ZnO}$ seed layer [24]. This finding also can be supported with the morphology obtained by FESEM images. The distribution and growth of $\mathrm{ZnO}$ nanorods enhanced with the increase of seed layer number. However, the peak intensity decrease when further number of seed layer increased. This condition might occur due to the misalignment of the $\mathrm{ZnO}$ nanorods during growth process. The explanation behind this occurrence is the seed/rod number ratio in the formation of single rod. As correlated with morphology and diameter value obtained, misalignment could happen when there are multiple nanorods that growth from a single seed. This type of growth process may lead to the misalignment rod, thus affect the crystallinity of $\mathrm{ZnO}$ nanorods. This finding is supported with the study reported by B. Ikizler et al. They also obtained the same finding, when the thickness of the seed layer is increased.

For optical properties, the characterization was conducted using UV-Vis. The transmittance and absorbance of the grown $\mathrm{ZnO}$ nanorods are shown in the Fig. 4 (a) and (b), in the wavelength range of $350-800 \mathrm{~nm}$. Based on the results, the transmittance of the $\mathrm{ZnO}$ nanorods grown shows high percentage with the range of $50 \sim 95 \%$ in the visible range. As present in Fig. 4 (a), the transmittance of the $\mathrm{ZnO}$ nanorods decrease with the increasing number of seed layers. $\mathrm{ZnO}$ nanorods grown on 1 layer of seed layer gave highest transmittance value, which is $\sim 95 \%$. This percentage decrease significantly when further number of seed layer increase, because of the higher absorption capacity of thicker films. Besides, B. Ikizler et. al, stated that the percentage of transmittance would decrease in the UV region due to the onset of excitoic absorption [28]. Other than that, the increase in the sharpness of the transition from the UV to the visible region transmittance can be considered as the crystalline quality improvement for the films [30].

As for the optical absorbance, the absorption properties of the $\mathrm{ZnO}$ nanorods with different layer of seed layer increase proportionally to the seed layer numbers at UV region (below $400 \mathrm{~nm})$ and lower at visible region (400-800 nm). According to the result, $\mathrm{ZnO}$ nanorods grown on 5 layers of seed layers shows maximum UV absorbance value. Based on the transmittance and absorbance value, the optical energy band gap, $\mathrm{E}_{\mathrm{g}}$ for $\mathrm{ZnO}$ grown on different seed layer could be determined using Eq. (6) below :

$$
E g=\frac{h c}{\lambda}
$$

$$
\begin{aligned}
& \text { Where, } \\
& \mathrm{h}=\text { Plank constant } \\
& \mathrm{c}=\text { light constant } \\
& \lambda=\text { Wavelength }
\end{aligned}
$$

Based on the calculation, the $\mathrm{E}_{\mathrm{g}}$ of the $\mathrm{ZnO}$ nanorods grown in this study were found to be in range of $3.34-4.10 \mathrm{eV}$. These findings were presented in Table 3. Optical energy band gap of $\mathrm{ZnO}$ nanorods increase directly proportional with the number of seed layers. This increment occur due to the thickness of the films that increase when the number of seed layer was increased. Increasing number of layer would produce thicker film, which influence the transmittance, absorbance, as well as optical energy band gap. Other than that, the increase in band gap value is also might attribute to the increase of grain size and strain, as stated by B. Ikizler [28]. This grain size would increase if the thickness or chemical composition is increased. These two factors will directly changed the material (thin film) band gap [31]. Even though the same material was used, the optical energy band gap would changes significantly with the changes of thickness and chemical composition. Other than that, crystallinity, temperature, particles size and few other factors will also affect the value of the energy band gap of thin film [32].

TABLE III

OPTICAL ENERGY BAND GAP FOR ZNO NANORODS GROWN ON DIFFERENT LAYER OF SEED LAYER

\begin{tabular}{cc}
\hline \hline NuMBER OF LAYER & Optical band gap (eV) \\
\hline 1 & 3.34 \\
3 & 3.43 \\
5 & 4.10 \\
\hline \hline
\end{tabular}



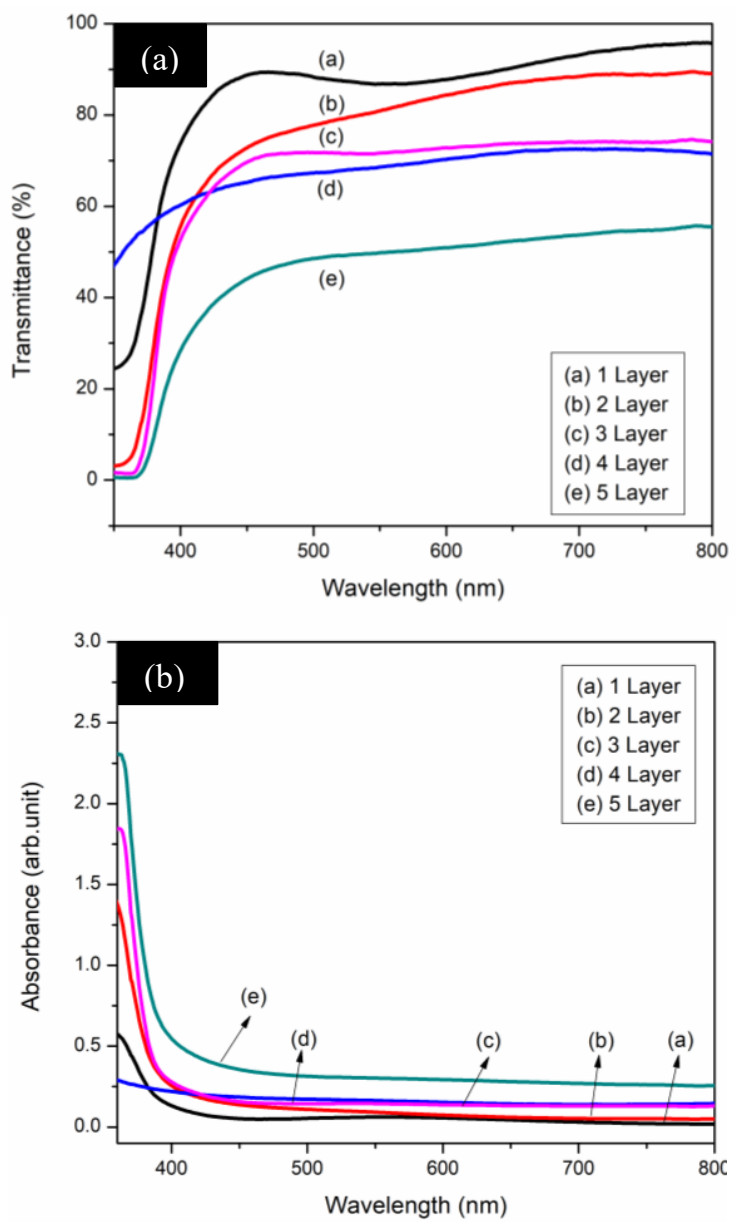

Fig. 4. (a) Transmittance of $\mathrm{ZnO}$ nanorods with different seed layer and (b) Absorbance for all $\mathrm{ZnO}$ nanorods grown on different number of seed layer

\section{CONCLUSION}

$\mathrm{ZnO}$ nanorods with various number of seed layers were successfully grown via two-step process; spin coating technique and chemical bath deposition. Based on the investigation, it is proved that physical, morphology, structural and optical properties of the $\mathrm{ZnO}$ nanorods were influence by the thickness or number of seed layers. The film become thicker when number of layers were added, thus affect the surface morphology of the $\mathrm{ZnO}$ nanorods. Nanorods are dense and well-align at thicker film, as shown by the FESEM images obtained. The increment number of layer contribute to the uniform distribution of the $\mathrm{ZnO}$ seed layer on the surface of the substrate. Deposition of another layer of seed layer can improve the previous deposited layer in order of uniformity, hence thicker seed layer with dense surface will be produced. Other than that, the crystallinity quality was improved also when the thickness increase, which the intensity of (100),(002) and (101) peak gave highest value at $\mathrm{ZnO}$ nanorof grown on 3 layers of seed layer. However, $\mathrm{ZnO}$ nanorods grown on 5 layer seed layer exhibit lower intensity, compared with 3 layer of seed layer. Misalignment of the grown nanorods and decrease of the nanorods diameter maybe are the causes to this occurrence. The transmittance and absorbance value also gave better value when the seed layer is increased, hence produce high optical energy band gap with the average value of $3.53 \mathrm{eV}$.

\section{ACKNOWLEDGMENT}

The authors would like to thank all members of Nano Electronic Center (NET), Integrated Sensor Research Group (DERIA) and Nano-Science Technology Center (NST), Universiti Teknologi MARA (UiTM) Shah Alam for all the research facilities. This work is partially supported by the Ministry of Higher Education Malaysia under Fundamental Research Grant Scheme (600-IRMI/FRGS 5/3 (080/2017)).

\section{REFERENCES}

[1] X. Cheng, "Nanostructures: fabrication and applications," Woodhead Publishing Limited, pp. 348-374, 2014.

[2] H. G. Craighead, "Nanostructure science and technology: Impact and prospects for biology," Journal of Vacuum Science \& Technology A, vol. 216, no. 2003, 2014.

[3] S. Mobasser and A. A. Firoozi, "Review of Nanotechnology Applications in Science and Engineering," Journal of Civil Engineering and Urbanism, vol. 6, no. 4, pp. 84-93, 2016.

[4] R. Seqqat, L. Blaney, D. Quesada, B. Kumar, and L. Cumbal, "Nanoparticles for Environment, Engineering, and Nanomedicine," Journal of Nanotechnology, vol. 2019, pp. 1-2, 2019.

[5] T. Xu, P. Ji, M. He, and J. Li, "Growth and Structure of Pure ZnO Micro / Nanocombs," Journal od Nanomaterials, vol. 2012, pp. 1-5, 2012.

[6] R. Singh, K. Verma, A. Patyal, I. Sharma, and P. B. Barman, "Nanosheet and nanosphere morphology dominated photocatalytic \& antibacterial properties of $\mathrm{ZnO}$ nanostructures," Solid State Sci., vol. 89, no. October 2018, pp. 1-14, 2019.

[7] G. Ali, Y. J. Park, A. Hussain and S. O. Cho, "A novel route for the for the formation of 3D nanoflowres like hierachical iron oxide nanostructures, " Nanotechnology, vol. 30, no. 9, pp. 1-30, 2018.

[8] K. O. Ukoba and F. L. Inambao, "Review of nanostructured $\mathrm{NiO}$ thin film deposition using the spray pyrolysis technique," Renew. Sustain. Energy Rev., vol. 83, no. 3, pp. 2900-2915, 2017.

[9] R. Verma and A. K. Srivastava, "Multiphase $\mathrm{TiO}_{2}$ nanostructures : A review of efficient synthesis, growth mechanism, probing capabilities, and application in bio-safety and health," RSC Adv., vol. 7, no. 70, pp. 4419944224, 2017.

[10]T. Zhang, S. Wu, R. Yang, and G. Zhang, "Review article Graphene: Nanostructure engineering and applications," Frontier Physics, vol. 12, no. 1, pp. 1-22, 2017.

[11]Y. Peng and L. Bao, "Controlled-synthesis of $\mathrm{ZnO}$ nanorings," Front. Chem. China, vol. 3, no. 4, pp. 458-459, 2008.

[12]S. Yang, Y. Wang, L. Wang, G. Zhang, A. Vazinishayan and A. Duongthipthewa, "Growth and characterization of ultra-long $\mathrm{ZnO}$ nanocombs Growth and characterization of ultra-long $\mathrm{ZnO}$ nanocombs," AIP Advances, vol. 6, no. 6, pp. 065209-1-4, 2016.

[13] Y. Xi, C. G. Hu, X. Y. Han, Y. F. Xiong, P. X. Gao, and G. B. Liu, "Hydrothermal synthesis of $\mathrm{ZnO}$ nanobelts and gas sensitivity property," Solid Satete Communication, vol. 141, no. 9, pp. 506-509, 2007.

[14]G. Yi, C. Wang, and W. Il Park, "ZnO nanorods: synthesis , characterization and applications," Semiconductor Science and Technology, vol. 22, no. 4, pp. S22-S34, 2005.

[15]A. A. Ghassan, N. A. Mijan and Y. H. Taufiq-Yap, "Nanomaterials: An Overview of Nanorods Synthesis and Optimization," [Online First], IntechOpen, DOI: 10.5772/intechopen.84550.

[16]A. Cheng, Y. Tzeng, Y. Zhou, M. Park, T. Wu, C. Shannon, D. Wang and W. Lee, "Thermal chemical vapor deposition growth of zinc oxide nanostructures for dye- sensitized solar cell fabrication," Applied Physics Letter, vol. 092113, no. 2008, pp. 18-21, 2013.

[17]S. N. Das, J. P. Kar, J. Xiong, and J. Myoung, "Synthesis of ZnO Nanowire by MOCVD Technique: Effect of Substrate and Growth Parameter," Nanowires- Recent Advances, Intech Open, Chapter 2, 2012.

[18]C. F. Mah, "Investigation and characterization of $\mathrm{ZnO}$ Nanostructures synthesized by electrochemical deposition," Procedia Chem., vol. 19, pp. 83-90, 2016.

[19]B. A. Ezekoye, P. O. Offor, V. A. Ezekoye, and F. I. Ezema, "Chemical Bath Deposition Technique of Thin Films:A Review," International Journal of Scientific Research, vol. 2, no. 8, pp. 2-6, 2013. 
[20]Q. Li et al., "Controllable growth of well-aligned $\mathrm{ZnO}$ nanorod arrays by low-temperature wet chemical bath deposition method," Applied Surface Science, vol. 256, no. 6, pp. 1698-1702, 2010.

[21]G. Amin, M. H. Asif, A. Zainelabdin, S. Zaman, O. Nur and M. Willander, "Influence of $\mathrm{pH}$, precursor concentration, growth time, and temperature on the morphology of $\mathrm{ZnO}$ nanostructures grown by the hydrothermal method," Journal of Nanomaterials, vol. 2011, 2011.

[22]D. Polsongkram, P. Chamninok, S. Pukird, L. Chow, O. Lupan, G. Chai, H.. Khallaf, S. Park, and A. Schulte, "Effect of synthesis conditions on the growth of $\mathrm{ZnO}$ nanorods via hydrothermal method," Physica B, vol. 403, no. 9 , pp. 3713-3717, 2008.

[23] J. B. Cui, C. P. Daghlian, U. J. Gibson, R. Püsche, and P. Geithner, "Lowtemperature growth and field emission of $\mathrm{ZnO}$ nanowire arrays," Jorunal of Applied Physics, vol. 97, no. 4, 2005.

[24] S. Pokai, P. Limnonthakul, M. Horprathum, and P. Eiamchai, "Influence of seed layer thickness on well - aligned $\mathrm{ZnO}$ nanorods via hydrothermal method," Mater. Today Proc., vol. 4, no. 5, pp. 6336-6341, 2017.

[25]A. Basar, S. Debnath, and A. B. Ismail, "An experimental study on the effect of film layer and annealing on morphology by AFM of tin dioxide thin film prepared by spin-coating method." Material Research Express, vol. 1, no. 2, pp. 026402, 2014.

[26] M. Addamo, V. Augugliaro, A. Di Paola, V. Loddo, G. Marcì, and L. Palmisano, "Photocatalytic thin films of $\mathrm{TiO}_{2}$ formed by a sol-gel process using titanium tetraisopropoxide as the precursor," Thin Solid Film, vol. 516, no.12, pp. 3802-3807, 2008.

[27]A. R. Marlinda, N. Yusoff, A. Pandikumar, N. M. Huang, O. Akbarzadeh, S. Sagadevan, Y. A. Wahab and M. R. Johan., "Tailoring morphological characteristics of zinc oxide using a one-step hydrothermal method for photoelectrochemical water splitting application," Int. J. Hydrogen Energy, vol. 44, no. 33, pp. 17535-17543, 2019.

[28]B. Ikizler, and S. M. Peker, "Effect of the seed layer thickness on the stability of ZnO nanorod arrays," Thin Solid Film, vol. 558, no. March, pp. 149-159, 2014.

[29] W. Wu, C. Yeh, and J. Ting "Effects of Seed Layer Characteristics on the Synthesis of ZnO Nanowires," Journal of the American Ceramic Society, vol. 2723, pp. 2718-2723, 2009.

[30]S. Mridha and D. Basak, "Effect of thickness on the structural , electrical and optical properties of $\mathrm{ZnO}$ films," Material Research Bulletin, vol. 42, no. 5, pp. 875-882, 2007.

[31]A. Bedia, F. Z. Bedia, M. Aillerie, N. Maloufi and B. Benyoucef, "Influence of the thickness on optical properties of sprayed $\mathrm{ZnO}$ holeblocking layers dedicated to inverted organic solar cells," Energy Procedia, vol. 50, no. 2014, pp. 603-609, 2014.

[32]C. V. Ramana, R. J. Smith, and O. M. Hussain, "Grain size effects on the optical characteristics of pulsed-laser deposited vanadium oxide thin films", Rapid Research Note, vol. a, no.199, pp. R4-R6, 2003. 